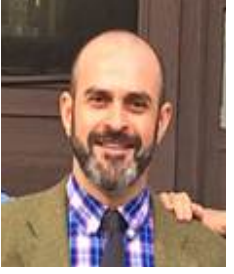

\title{
Mobile apps and translation crowdsourcing: The next frontier in the evolution of translation
}

\author{
Miguel A. Jimenez-Crespo, PhD \\ Rutgers University, The State University of New Jersey \\ USA
}

\section{ABSTRACT}

Mobile translation represents the new frontier in the translation industry enabled by constant developments in connectivity, apps and micro-task crowdsourcing workflows. It involves a brand new approach to professional and volunteer translation that has not been explored to date. This article analyzes the intersection of crowdsourcing and its micro-task approach and smartphone apps, and also charts how the relationship between apps and translation has evolved during the last decade. Basic notions such as mobile translation, mobile human translation, translation crowdsourcing and online community translations are defined, and the different stages in the evolution of mobile translation are described. The paper ends with a description of initiatives that have relied on cell phone SMS or smartphone apps to translate, ranging from initiatives such as TxtEagle to industry innovators such as Unbabel and Stepes.

Keywords: Crowdsourcing, volunteer translation, mobile translation, mobile human translation, community translation, SMS translation

\section{RESUM}

La traducció mòbil representa una de les àrees més dinàmiques de la traducció a causa dels constants avenços en connexió, aplicacions i fluxos de microtasques de traducció col-laborativa, que representen un nou enfocament a la traducció professional i voluntària. Aquest article analitza la intersecció de la traducció collaborativa en la seva dimensió de microtasca i les aplicacions de telèfons intel-ligents per tal de traçar l'evolució de la relació entre les aplicacions i la traducció. S'hi defineixen les nocions bàsiques de traducció mòbil, traducció collaborativa i traducció comunitària, i es descriuen les fases de l'evolució de la traducció mòbil.

Paraules clau: traducció col·laborativa, aplicacions mòbils, traducció mòbil

\section{RESUMEN}

La traducción móvil representa una de las áreas más dinámicas de la traducción a causa de los constantes avances en conexión, aplicaciones y flujos de microtareas de traducción colaborativa, que representan un nuevo enfoque a la traducción profesional y voluntaria. Este artículo analiza la intersección de la traducción colaborativa en su dimensión de microtarea y las aplicaciones de teléfonos inteligentes con el fin de trazar la evolución de la relación entre las aplicaciones y la traducción. Se definen las nociones básicas de traducción móvil, traducción colaborativa y traducción comunitaria, y se describen las fases de la evolución de la traducción móvil.

Palabras clave: traducción colaborativa, aplicaciones móviles, traducción móvil

\section{Introduction: Of translation, crowdsourcing and mobile apps}

It can be argued that the next wave of innovation in the world of translation is coming through the mobile revolution empowered by technology platforms and unlimited networking capabilities. Nowadays, millions of bilingual smartphone, tablet and wearable users around 
the world, including professional translators, carry these gadgets around 24/7. These gadgets include applications that help people stay connected to their peers, language industry key players and the WWW. They also serve as an extension of human cognition, assisting and extending cognitive processing and problem solving beyond the confines of the human mind (Smart, 2014; Whitaker, Chortly and Allan, 2015). In this context, this paper departs from the intersection of two new phenomena that can continue to expand the limits and reaches of translation in our technological world: (1) the expansion of translation crowdsourcing (Jiménez-Crespo, forthcoming a) and (2) initiatives that provide MT, post-edited MT, and volunteer and professional translation crowdsourcing through smartphone apps. New apps nowadays engage communities of smartphone users with translation and translation technologies in ways that were unimaginable a decade ago. This revolution goes beyond the extremely popular social networking apps: users-developers can ask for their apps to be localized into their language of choice using crowdsourcing, MT apps can request users to help improve the translation output; travelers can request the help of the crowd to translate a photo of any street sign by means of sending a photo request to the Linqapp or UbiAsk communities. This revolution in which humans produce and deliver translations while engaging in different technologies through smartphones has already been set in motion.

The integration of these different types of translation processes into smartphones is helping extend translation processes beyond the classic "translation workstation" or "workbenches" (Sommers, 2003). "Translation workstations" or "workbenches" are defined as "personal computers [...] [where] the translator [is] provided with software and other computer-based facilities to assist in the task of translation" (Sommers, 2003:7), a concept which has not evolved much since the 80 's. It still conjures images of a computer with a mouse and keyboard, one or two screens and Internet access. However, it is now morphing in some specific cases into a smartphone or tablet that can potentially become a "minimal and ubiquitous" translator's workstation for professionals, who are defined here as those who make a living from translation (Pym, 2003). In this context, the goal of this paper is to analyze the novel ways in which smartphones and their apps have helped foster the creation of new translation scenarios, both in how translations are requested and distributed around the world, as well as how they are produced. This paper therefore does not deal with app localization in a strict sense, but rather mainly discusses the merging and interrelation of two new phenomena that need further exploration in Translation Studies (TS) and its "technological turn" (O'Hagan, 2013): the new dynamic notions of "mobile translation" and volunteer and professional crowdsourced translations (Jiménez-Crespo, 2015; forthcoming a).

\section{Mobile translation}

Translation through mobile apps must also be situated within the wider paradigm of "mobile crowdsourcing". This notion involves leveraging the wide distribution and use of mobile phones in order to crowdsource small micro tasks, such as translation, transcription, surveys, news reporting, emergency reporting, etc. (Gonçalves et al, 2015). In this context, language industry experts have introduced the notion of "mobile translation." According to Armstrong (2016), the blog from the translation crowdsourcing app Stepes states that "mobile translation" in its current context is often understood to be comprised of three distinct and interrelated phenomena: (1) the localization of apps; (2) the use of MT apps; and (3) the use of apps inspired by crowdsourcing workflows to carry out human translation either though post editing MT or through direct human translation. This paper is focused on the latter, which will be referred to hereinafter as "crowdsourced mobile human translation."

Historically, the first phenomenon referred to as "mobile translation" was related to the localization of mobile apps or any other textual genre associated with cell phones. Crowdsourcing and volunteer translation has been used to localize apps with initiatives such as those by Ackuna or El Loco. For example, the company El Loco automates the app localization process and includes the possibility of crowdsourcing the translation stage. This 
company, which was developed by the language service industry Verbalizeit, takes a visual localization approach, helping prepare for localization from the development stage. In EI Loco, the localization of apps can be carried out through a variety of ways, such as by MT, crowdsourcing or by having developers perform the translation tasks directly. In instances that contain critical content, clients can request professional services (this is recommended for critical information such as navigational, legal or medical information on the website of this company). Ackuna, on the other hand, is a successful online platform in which crowdsourced volunteer translations of apps can be requested. Both initiatives depart from the premise that crowdsourcing or MT projects can be requested, and professional services are also offered for those cases in which the crowd might not complete a project or the requestors believe a higher quality product is needed. In the latter case, clients need to decide which level of quality and price to request, often choosing an associated process to produce the translation (i.e. high quality professional translation, crowdsourcing to professionals, to volunteers, with our without revision, etc.) (Jiménez-Crespo, forthcoming b).

Another definition of the notion of "mobile translation" is the use of mobile MT translation apps. Several MT translation apps exist with different architectures, such as Google Translate, ITranslate (for translating voiced or written phrases and websites using Systrans), Waygo (for Chinese, Japanese and Korean), etc. Many of these apps offer the possibility of image translation, in which a photo that includes text is sent and the app uses OCR (Optical Character Recognition) technology to recognize the text, while also producing a MT rendering of the scanned text. This last option, the translation of the text in images sent via an app, has also been explored through the volunteer crowdsourcing model in an initiative by UbiAsk. Through this app, users can upload images containing different languages and other users that know the particular language will respond to the image and translate the content (Liu et al, 2012).

The last and more recent meaning of "mobile translation", or rather "crowdsourced mobile human translation," includes initiatives that have brought the world of professional (or para-professional) translation to mobile apps. Armstrong defines this third type of mobile translation as using "mobile apps [that] allow professional translators to translate everywhere" (2016: np). This paper specifically defends referring to this notion as "crowdsourced mobile human translation," rather than simply as "mobile translation," because for several years cloud TM systems, such as Wordfast Anywhere, have implemented the possibility of using such systems via smartphones and tablets. Thus, "mobile human translation" includes both the use of cloud TM systems and the use of translation crowdsourcing apps. The latter includes companies such as Stepes and Unbabel, which have developed their workflows and business models to leverage existing crowdsourcing workflows, micro-task crowdsourcing technologies and app technologies from other domains, as well to take advantage of the fact that cell phones are carried everywhere. Such companies have expanded translation beyond the realm of the classic "translation workstation"; professional translators do not have to rely exclusively on desktop or laptop computers. Also, technological competencies, which encompass part of the contemporary profile of the professional translator, are not required. The responsibility to learn and proficiently manage translation technologies is lifted from the translators, since they do not have to set up translation memories, terminology databases or MT systems; rather, the workflows are set up and managed by the initiating companies. Thus, smartphones with carefully designed apps have emerged as the new frontier for freelance translators or "talented bilinguals" to make a living or complement their incomes.

It will be seen whether this new approach, in which bilinguals and professionals can be classified in terms of skills, potential income or responsibility depending on several variables, will consolidate in the near future. The issue, as DePalma indicates, is whether companies in this new "paid crowdsourcing" (Garcia, 2015) will be willing to compensate users enough to motivate them to participate.

It remains to be seen whether the price that seems attractive to bilinguals gains a significant uptake in commercial applications. If buyers are willing to pay what mobile 
users deem a worthy wage, no doubt there will be many years, conferences, and forums spent debating the merits. (DePalma, 2015:np).

What is clear is that the dynamicity and ingenuity that these new initiatives bring to the language industry, irrespective of whether they will succeed or not, can help continue to expand the notion of translation to contexts and situations where it was unthinkable just a decade ago. Thus, the translation industry is being propelled forward in tune with new technologies.

\section{Translation crowdsourcing}

Generally, the term crowdsourcing is attributed to Howe (2006), who created this compound term by joining the words "crowd" and "outsourcing." Crowdsourcing represents a practice firmly grounded in the participatory nature of the Web 2.0, and it has been used by businesses, organizations, institutions and collectives to harness the wisdom of the crowd, consisting of a large group of amateurs, experts, volunteers, professionals, fans or citizens, to accomplish any given task. In Translation Studies, this term has been defined as a novel, burgeoning practice by which translations are being produced in some sort of collaborative process by volunteer groups of Internet users who form an online community (O'Hagan, 2013). Despite the fact that crowdsourcing is usually used as a synonym for all types of volunteer/non-professional translations done by volunteer communities on the web,, it is necessary to separate two different concepts that share a common space: on the one hand, "translation crowdsourcing" and on the other, "online collaborative translation" (Fernandez Costales, 2012; Jimenez-Crespo, 2015). The former can be defined as:

Collaborative translation processes performed through dedicated web platforms that are initiated by companies or organizations and in which participants collaborate with motivations other than those strictly monetary. (Jiménez-Crespo forthcoming a: np).

Translation crowdsourcing now includes initiatives by the language industry (i.e. Getlocalization), social networking sites (Facebook, Twitter), software companies (Adobe, Skype), non-profit organizations (Translators without Borders, Rosetta Stone or Kiva), or popular audiovisual initiatives (TED Talks Open Translation Project, Viki). The definition of crowdsourcing includes the fact that its models can include a range of payments in their crowdsourcing efforts, from small phone credits such as those by TxtEagle or MobileWorks (see section 4), all the way to professional payments in crowdsourcing business models that offer the possibility of what is known as "selected or specialized" crowds of selected or certified specialized translators. In this sense, translation crowdsourcing includes both free and "paid crowdsourcing" (García, 2015) models, with a very flexible range of payments in an unprecedented expansion of the translation business model (Jimenez-Crespo, forthcoming b). This is primarily the approach that has expanded to use crowdsourcing through mobile apps and that has fostered the emergence of a new professional translation model.

The second notion, the notion of "online collaborative translations," can be defined as "collaborative translation processes in the web initiated by self-organized online communities in which participants collaborate with motivations other than monetary." In this case, collectives of Internet users organize themselves to translate any content that motivates communities to participate, such as TV series (Orrego-Carmona, 2014, 2015), videogames (O'Hagan and Mangiron, 2014) and manga (O'Hagan, 2006). This type of web-mediated collaborative translation occurs primarily by use of computers and has yet to jump to the mobile revolution. Some peer-to-peer app initiatives exist, such as the Linqapp, HelloTxt and Flitto, in which users receive points by helping others with translations; in return, they can also request translations of texts, audio, images, etc. from the community. Nevertheless, these initiatives are directed from the bottom-up and their companies have an interest in monetizing user participation. 
Now that the working concepts in this paper have been briefly outlined and delimited (see Jiménez-Crespo, 2015, forthcoming a, for a more detailed conceptual/epistemological discussion), the next section explores the evolution of mobile human translation from cell phones and text messaging to crowdsourcing translation apps.

\section{The evolution of mobile human translation: Crowdsourcing translation through texting to texting workflows to translate}

The relation between translation and smartphones did not start until around 2010 when the first MT Google Translate App for Android appeared, or until 2012 when the free language learning and translation app Duolingo ${ }^{1}$ was launched, or even until 2014 with the appearance of the Unbabel professional crowdsourcing translation app. It can be argued that the relation between mobile phones and translation started through crowdsourcing projects that took advantage of the more widespread availability of cell phones and text messaging, rather than computers, in developing countries. Crowdsourced mobile human translation started in developing nations with projects such as TxtEagle (Eagle, 2009), a platform now called "Jana." This initiative was launched in 2009 in Kenya and Rwanda and has been expanded to other countries over time. It did not entail using mobile apps, but rather text messaging, to distribute micro tasks, such as the transcription and translation of oral texts between different languages spoken in these countries to cellphone users. Translations could be completed anywhere and returned via text messaging. In return, these micro tasks were compensated through airtime credit or mobile money called M-Pesa. The foundation for this type of payment was that companies developed a system to transfer airtime credit between users, a system that quickly started to be used to make micropayments for different tasks. Initially, the types of tasks deployed involved the transcription of audio in different languages, the translation of strings for software localization in the 15 languages spoken in Kenya or the translation of news. Over the years, several other initiatives have emerged in Asia, such as MobileWorks (Narula, 2011) or mClerk (Gupta et al, 2012). This last initiative, for example, involved receiving images through SMS that users could either translate or transcribe.

\section{Smartphone apps for crowdsourcing human translation}

The actual world of "crowdsourced mobile human translation" via apps can be subdivided into three distinct areas: (1) smartphone apps for websites that adapt existing crowdsourcing initiatives (i.e. the Translate Facebook app); (2) language learning initiatives that include translation crowdsourcing, such as Duolingo or Linqapp; and (3) new ventures in the language industry, such as Unbabel or Stepes, in which communities, both non-professional and professional, can perform translations following a micro-task approach.

The first category involves the adaptation of existing crowdsourcing initiatives from websites to their smartphone apps. In the case of Facebook, for example, any user that has enabled the Translate Facebook application on the website can also access it via the smartphone app. Nevertheless, this app offers a user interface (UI) and interactivity options that are completely different from the ones in the web browser version. The smartphone app, once activated, immediately displays one segment to translate with its existing translation proposal. Users can either: (1) select an existing proposed translation; (2) report a translation; (3) propose a new translation; or (4) skip to another segment. In the application for web browsers, the UI has more interactivity options, and several materials to achieve consistency, such as glossaries, style guides and forums. As an example, the option to report a translation opens up a menu which displays four different options to report inadequate translations, such as "wrong style or wording" or "wrong meaning." In this sense, the app offers a limited experience, even though it entails a more direct and intuitive approach.

${ }^{1}$ Duolingo can also be used in its web version in computers. 
The second area of development of human crowdsourced translation in smartphones encompasses language-learning apps, such as Duolingo or Linqapp. In certain cases, as is the case with Duolingo, a web version also exists. These apps include the possibility of performing volunteer translation tasks, which ultimately benefit the companies. Duolingo has represented a classic example of crowdsourcing translation to language learners since 2012 (García, 2012). Its model originally involved having language learners learn or improve language skills through both direct translation and voting among proposed translations of textual segments of increasing difficulty. The textual segments were extracted from actual translation tasks that certain organizations would provide to Duolingo for a fee. For example, CNN and Buzzfeed initially entered into an agreement with Duolingo to translate the content of these two companies through Duolingo's crowdsourcing workflow. Later in 2014, Duolingo attempted to expand to the realm of professional translation through its crowdsourcing models, using its Test Center to certify or qualify users with higher skills who would enter Duolingo's specialized crowd. Nowadays, this model is used by a large number of companies in the language service industry to provide crowdsourced translation services of higher standards. However, Duolingo discarded this translation business model in mid 2015.

Other types of apps that can be used to learn a language and that crowdsource translations include user-to-user initiatives such as Flitto, HelloTalk or Linqapp. This last one brands itself as a complement to users who have already used other language learning apps, such as Duolingo. Its design is intended for translation, cultural exchange and language questions. Its initial approach is similar to the platform used by Cucumis, which entails a type of bartering in which users initially receive points when they request translations or other services; after users use up their initial credit, they are required to answer questions proposed by other users in order to gain additional "credits." The Linqapp model attempts to differentiate itself from other MT translation apps by offering the possibility of providing translations of audio recordings or pictures taken by humans, tasks that can also be completed with lower success ratios via several MT-based translation apps ${ }^{2}$. The company also offers the possibility of monetizing user participation through their Linqapp Live feature. If users need immediate help and have run out of credits, they can still request a live connection with a speaker of whichever language for which they need translation or cultural assistance, costing less than one dollar for five minutes ${ }^{3}$. This small fee, however, does not get awarded to the participants that help, since these participants do the service strictly for reputation and app credit purposes.

The most recent business model to take advantage of the wisdom and power of the crowd is that of companies which have ventured into smartphone app translation through crowdsourcing models. One of the companies leading the way is Unbabel, which launched its web browser-based and app-based crowdsourcing platforms for volunteers and professional translators in 2014. The company can be located within the blended model which incorporates both volunteer and "paid crowdsourcing" models to translate content. In the case of this company, it is up to both the client and the translators on each side to engage with either option. Unbabel uses Human-Assisted Machine Translation (HAMT) approaches, providing an MT translation that users post-edit on their cell phones. Due to this fact, Unbabel, for example, stresses an hourly rate model for professional translators rather than a per-word classic approach. Translators-editors are therefore paid according to time spent performing post-editing tasks; in the summer of 2016, this rate started at eight dollars with the possibility of earning eighteen dollars per hour as the maximum rate, depending on the quality and efficiency of the time spent during the post-editing process. The acceptance process for participants in Unbabel includes a series of testing of language and translation proficiency. Once accepted, participants have to rate translations and provide post-edited translations that are subsequently rated by others. According to the company website, only the best-rated translators can get paid tasks. Unbabel stresses that the translation community includes

\footnotetext{
${ }^{2}$ Such as the image translate function in the Google Translate app.

${ }^{3} \mathrm{https}$ ://www.techinasia.com/linqapp-live-launch-real-time-human-translation
} 
"professional translators and native speakers," supposedly classifying as professionals those who excel in their peer reviews and performance at the tasks offered by the company. The potential to be selected as an editor for paid tasks therefore depends on the results of admission tests and reviews of performance by peers, which includes a review trustworthiness business model similar to those from other realms, such as those of Uber or Airbnb.
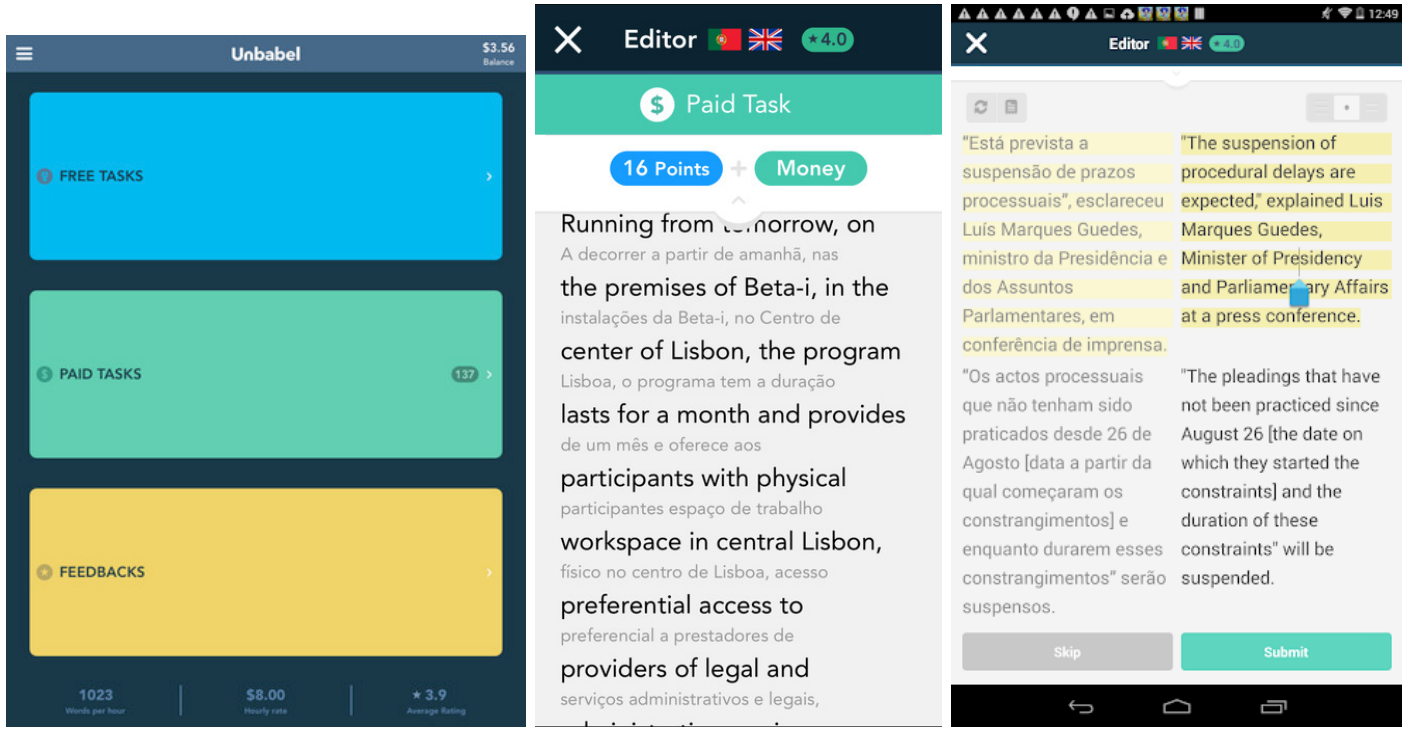

Figure 1. The user interface of the Unbabel translation app.

The user interface of the translation app includes a basic menu that displays options such as translating free tasks, translating paid tasks, feedback and current credit. At any time, users can transfer their balance to their PayPal accounts. The crowdsourcing of MT postediting has also come to smartphones in non-profit initiatives, such as the Kanjingo app by the Rosetta Foundation and the Centre for Next Generation Localization in Ireland. This app was presented in 2015 and is intended to "enable and assist with volunteer translation projects, particularly in crisis situations and in economies where people generally do not have access to computers but may have access to a smartphone"4.

The expansion of translation to smartphone technologies and apps can be considered to have been fully developed within the approach taken by the company Stepes. This initiative further moved the mobile app crowdsourcing translation market to a mobile-only paradigm by means of replicating the text-messaging interface. This could be considered the first initiative to base its model exclusively through smartphone apps, without a parallel website. This company offers a technology called "Swish" which replicates messaging apps in order to translate anywhere and anytime, deemed "chat based translation." The term "Swish" refers to the fact that translators can "swish," or "swipe," left or right to see the source text or target text, respectively (DePalma, 2015). Translators, once approved, download the Stepes app on their smartphones. The company uses TermWiki, also developed by the same individuals responsible for the creation of the app, to harness the availability of both the translator database and an extensive terminology database for their workflow. Once the project has been leveraged with existing translation memories (TMs) and terminology databases, it is ready to be sent to translators through a micro-task approach. All TMs and terminology databases are managed by Stepes. As opposed to Unbabel, this company does not use MT in its workflow. Instead, selected translators immediately receive a message on their cellphones indicating that a suitable project is ready for them. If accepted, they can start translating immediately in a segmental approach that displays one segment at a time in a UI

$\overline{{ }^{4} \mathrm{http} / / / w w w . t h e r o s e t t a f o u n d a t i o n . o r g / b l o g / k a n j i n g o-t h e-p o s t-e d i t i n g-a p p-f o r-v o l u n t e e r s / ~}$ 
that replicates smartphone messaging. The translator has available the number of total segments, as well as how many remain. Stepes, according to its website, uses "translation memory, spell checker and voice dictation [...] to improve the quality and increase translation productivity." The company stresses the fast turnaround that can be provided utilizing this new approach via smartphone apps and a massive crowd; the company refers to this as "hyper fast translation turnaround times." ${ }^{5}$ This means that the company specifically targets social media platforms, such as Facebook and Twitter, translation where speed is of the utmost importance. Nevertheless, the company also offers regular services for fields such as legal or medical.

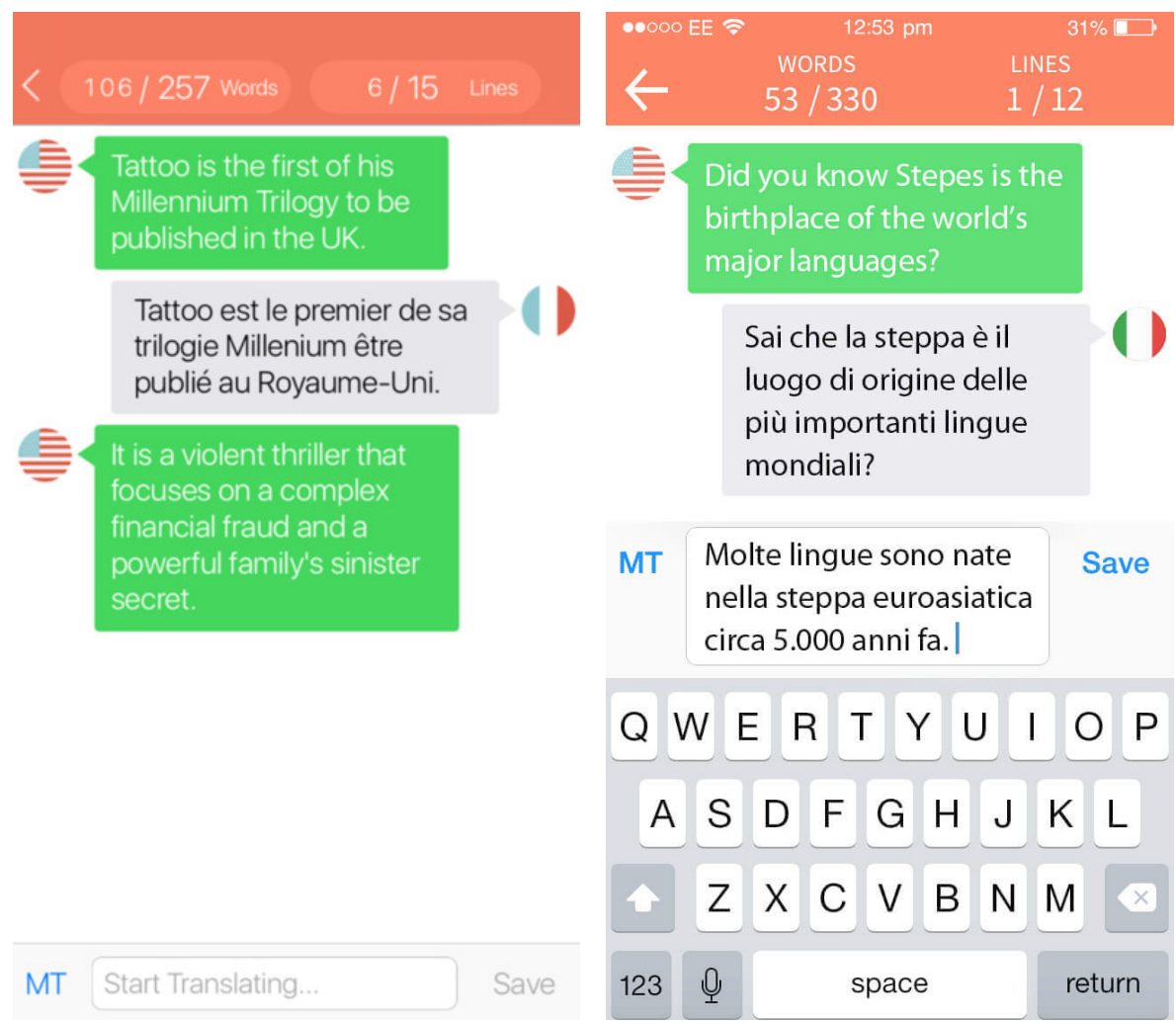

Figure 2. User interface for the chat-based crowdsourcing translation app Stepes.

This workflow model, in which projects are quickly assigned to a large crowd of potential translators who are immediately notified, is nothing new; companies such as Babelfish implemented this approach almost 15 years ago on the web. This smartphone approach through an app using a combination of micro-task paid crowdsourcing and a range of documentation and support mechanisms already prepared by the company (i.e. MT, TermWiki support, specialized TMs, turning smartphones into the translator's workstation, etc.) represents a new translation approach that deserves further study.

\section{Conclusions}

This paper has reviewed how the ubiquitous nature of smartphones and the emergence of translation initiatives that use smartphone apps are initiating a shift in the world of translation to include professional translation through paid crowdsourcing. It can be argued that this move is the "next frontier" in the expansion of MT, crowdsourced, volunteer, paraprofessional and professional translation. This next frontier involves a move from stationary "translators' workstations" at desks to the possibility of participating in crowdsourced translations

\footnotetext{
${ }^{5}$ https://www.stepes.com/just-in-time-translation/
} 
anywhere, anytime. The use of cell phones rather than computers to translate dates back to a decade ago when crowdsourcing platforms were used to translate SMS messages in crisis situations (Eagle, 2009; Meier and Munro, 2010). In this ongoing evolution, new business models based on micro-task crowdsourcing workflows via apps are now taking advantage of the ubiquitous presence of smartphones to attract bilinguals and professionals alike. The goal is to deliver flexible, dynamic and quick translations of varying degrees of quality (JiménezCrespo forthcoming b). It is still extremely early to predict whether the intersection of free and paid crowdsourcing approaches via smartphone apps will gain any traction in the coming years. Nevertheless, in the current era of "content prioritization" and with the de facto existence of different quality tiers in the translation industry for different content, contexts, user demands, etc., these types of initiatives will undoubtedly create a niche for themselves within the industry due to the never-ending need for speedy delivery of translations in the social network era (Jimenez-Crespo, 2013). The limitations of smartphones are clear in terms of screen space and, therefore, micro-task crowdsourcing workflows will continue to be the main approach in this area. Chiaro, discussing new forms of audiovisual translation in 2004, indicated the following:

The twenty first century is witnessing the advent of new technological devices for people's entertainment and interaction and the future is likely to bring new forms of translation which will be able to cope with the constraints of small, portable screens. These futuristic modalities are, at present, almost unimaginable (Chiaro, 2004: 163).

It seems like her prediction of certain unimaginable "futuristic modalities" is already a reality. The question now would be: what will be next? Only the ingenuity and imagination of the creative community of app developers and industry visionaries will tell.

\section{References}

Armstrong, T. (2016). "The evolution of mobile translation". Stepes Blogs. Available on the Web: https://blog.stepes.com/the-evolution-of-mobile-translation/

Costales, A. (2012). "Collaborative Translation Revisited: Exploring the Rationale and the Motivation for Volunteer Translation." Forum - International Journal of Translation 10:115-142.

DePalma, D. (2015). CSOFT Swipes Left for Translation, Right for the Source to Mobilize Translation." Common Sense Advisory. Available on the Web:

http://www.commonsenseadvisory.com/Default.aspx? Contenttype=ArticleDetAD\&tabID=63\&Aid=36417\&moduleld=390

García, I. (2012). "Learning a Language for Free While Translating the Web. Does Duolingo Work?" International Journal of English Linguistics 3:19-25.

García, I. (2015). "Cloud marketplaces: procurement of translators in the age of social media." Jostrans 23: 18-38. Available on the Web: http://www.jostrans.org/issue23/art_garcia.pdf

Gonçalves, J. et al. (2015). "Workshop on Mobile and Situated Crowdsourcing"

Proceedings of UbiComp/ISWC '15 Adjunct, September 07-11, 2015, Osaka, Japan. DOI: http://dx.doi.org/10.1145/2800835.2800966

Gupta, A. et al (2012). "mClerk: Enabling Mobile Crowdsourcing in Developing Regions." In Proceedings of CHI'12, May 5-10, 2012, Austin, Texas, USA. Available on the Web: http://www.cs.toronto.edu/ aakar/Publications/mClerk-CHI12.pdf

Howe, J. (2006). "Crowdsourcing: A Definition. Crowdsourcing: Tracking the Rise of the Amateur". Accessed March 2, 2016. Available on the Web: http://crowdsourcing.typepad.com/cs/2006/06/crowdsourcing_a.html 
Jiménez-Crespo, M.A. (2015). "Volunteer and Collaborative Translation". In Researching Translation and Interpreting, Claudia Angelelli and Brian Baer (eds.), p. 58-70. LondonNew York: Routledge.

Jiménez-Crespo, M.A. (Forthcoming a). Crowdsourcing and Online Community Translations: Expanding the Limits of Translation Studies.

Jiménez-Crespo, M.A. (Forthcoming b). "How much would you like to pay? Reframing and expanding the notion of translation quality through crowdsourcing and volunteer approaches." Perspectives: Studies in Translatology.

Liu, Y., Lehdonvirta, V., Alexandrova, T. and T. Nakajima. (2012). "Drawing on mobile crowds via social media. Case UbiAsk: image based mobile social search across languages." Multimedia Systems 18 (1): 53-67. Available on the Web:

http://vili.lehdonvirta.com/files/exec8102/Liu-2011-Drawing-on-mobile-crowds-via-socialmedia.pdf

O'Hagan, M. (2006). "Manga, Anime and Video Games: Globalizing Japanese Cultural Production." Perspectives - Studies In Translatology 14 (4): 243-247.

O'Hagan, M. (2013). "The Impact of New Technologies on Translation Studies: A Technological Turn?" In Routledge Handbook of Translation Studies, Carmen MillánVarela and Francesca Bartrina (ed.), p. 503-518. London: Routledge.

O'Hagan, M. and C. Mangiron. (2013). Videogame Localization. Amsterdam/Philadelphia: John Benjamins.

Orrego-Carmona, D. (2014). "Subtitling, video consumption and viewers: the impact of the young audience." Translation Spaces 3: 51-70.

Orrego-Carmona, D. (2015). The Reception of Non Professional Subtitling. PhD Thesis. University Rovira I Virgili, Spain. Available on the Web:

http://www.tdx.cat/bitstream/handle/10803/306439/Tesi?sequence=1

Narula, P. et al. (2011). "MobileWorks: A mobile crowdsourcing platform for workers at the bottom of the pyramid." In Proceedings of the AAAI Workshop on Human Computation (HCOMP'11), 121-123. Available on the Web: https://www.aaai.org/ocs/index.php/WS/AAAIW11/paper/download/3962/4263

Pym, Anthony. 2003. "Redefining Translation Competence in an Electronic Age. In Defense of a Minimalist Approach." META 48: 481-97.

Smart, Paul R. 2014. "Embodiment, Cognition and the World Wide Web." In The Routledge Handbook of Embodied Cognition, Lawrence Shapiro (ed.), p. 336-334. New York: Routledge.

Sommers, Harold. 2003. "The Translator's Workstation." In Computers and Translation: $A$ Translators Guide, Harold Sommers (ed), p. 13-30. Amsterdam-Philadelphia: John Benjamins.

Whitaker, Robert, Martin Chorley and Stuart Allen. 2015. "New Frontiers for Crowdsourcing: the Extended Mind." In Proceedings of the System Sciences HICSS, 2015 48th Hawaii International Conference on System Sciencies, p. 1635-1644. DOI: 10.1109/HICSS.2015.197. 